\title{
HUBUNGAN KUALITAS KOMUNIKASI GURU DAN SISWA DENGAN MOTIVASI BELAJAR MATEMATIKA
}

\author{
Qomsiatun Munawaroh, Moh. Bisri \\ Pendidikan Guru Madrasah Ibtidaiyah, Fakultas Ilmu Tarbiyah, IAIN Surakarta, Indonesia \\ E-mail: qomsiatunmuna@gmail.com
}

\begin{abstract}
The purpose of this study was to determine the relationship between the quality of teacher and student communication with the mathematics learning motivation of MI students. The research method used was correlational quantitative, and was carried out at MI Muhammadiyah Potronayan 1 Nogosari Boyolali from October 2020 to March 2021. The population in this study were all high-class students at MI Muhammadiyah in Nogosari Boyolali District. Sampling with cluster sampling technique as many as 63 students. The data collection technique uses a questionnaire that has been tested for validity and reliability. Based on the results of the study: The level of communication quality of teachers and students is included in the good category, which is $68.25 \%$. High grade students' motivation to learn mathematics is in the medium category, which is $61.90 \%$. Based on the calculation of the coefficient of determination (R2) of $17.8 \%$. The results of the correlation test with $r$ arithmetic $=0.422, r$ table $=0.244$, then obtained $r$ arithmetic $>r$ table, which shows there is a positive relationship between the quality of teacher and student communication with motivation to learn mathematics.
\end{abstract}

Keywords: Communication; Motivation to learn; Primary School

Abstrak Tujuan penelitian ini adalah untuk mengetahui adanya hubungan antara kualitas komunikasi guru dan siswa dengan motivasi belajar matematika siswa MI. Metode penelitian yang digunakan kuantitatif korelasional, dan dilaksanakan di MI Muhammadiyah Potronayan 1 Nogosari Boyolali di mulai bulan Oktober 2020 sampai maret 2021. Populasi dalam penelitian ini adalah seluruh siswa kelas tinggi di MI Muhammadiyah se- Kecamatan Nogosari Boyolali. Pengambilan sampel dengan teknik cluster sampling sebanyak 63 siswa. Teknik pengumpulan data menggunakan angket yang telah diuji validitas dan reliabilitasnya. Berdasarkan hasil penelitian: Tingkat kualitas komunikasi guru dan siswa termasuk kedalam kategori baik yaitu sebesar $68,25 \%$. Motivasi belajar matematika siswa kelas tinggi berada dalam kategori sedang yaitu sebesar61,90\%. Berdasarkan perhitungan nilai koefisien determinasi $\left(R^{2}\right)$ sebesar $17,8 \%$. Hasil uji korelasi dengan $r$ hitung $=0,422, r$ tabel $=0,244$, maka diperoleh $r$ hitung $>r$ tabel, yang menunjukkan terdapat hubungan yang positif antara kualitas komunikasi guru dan siswa dengan motivasi belajar matematika.

Kata Kunci : Komunikasi; Motivasi Belajar; Madrasah Ibtidaiyah 


\section{PENDAHULUAN}

Matematika merupakan salah satu mata pelajaran yang digunakan sebagai salah satu mata pelajaran dalam ujian nasional dan sering digunakan dalam kehidupan sehari-hari.. Setiap siswa mempunyai pandangan yang berbeda tentang pelajaran matematika. Bagi siswa yang menganggap matematika menyenangkan maka akan tumbuh motivasi dalam diri siswa untuk mempelajari matematika dan optimis dalam menyelesaikan masalah- masalah yang bersifat menantang dalam pelajaran matematika. Sebaliknya, bagi siswa yang menganggap bahwa matematika sebagai mata pelajaran yangsusah dan sulit, maka siswa akan bersikap pesimis dalam menyelesaikan masalah-masalah dalam pelajaran matematika dan kurang motivasi saat belajar matematika (Lestari, 2017: 76).

Fathurrohman dan Sulistyorini menjelaskan (2012: 140) motivasi belajar merupakan keseluruhan daya penggerak yang ada dalam diri individu (siswa)yang dapat menimbulkan kegiatan belajar dan memberikan arahan kegiatan belajar siswa untuk mencapai tujuan yang dikehendaki oleh siswayang bersangkutan dengan subjek belajar. Sedangkan Menurut Kompri (2017: 119), indikator motivasi yaitu: 1) Memiliki gairah yang tinggi, 2) Penuh semangat, 3) Memiliki rasa penasaran atau rasa ingin tahu yang tinggi, 4) Dapat bekerja sendiri, 5) Memiliki rasa percaya diri, 6) Memiliki daya konsentrasi yang tinggi, 7) Kesulitan dianggap sebagai tantangan yang harus dihadapi, 8) Memiliki kesabarandan daya juang yang tinggi.

Menurut Ridwan (2016: 49) faktor-faktor yang mempengaruhi motivasi belajar ada 2 yaitu faktor internal dan faktor eksternal. Faktor internal seperti siswa mempelajari mata pelajaran karena siswa menyenangi pelajaran tersebut. Faktor eksternal meliputi 1) karakteristik tugas; 2) intensif; 3) guru; dan 4) pengaturan pembelajaran. Faktor eksternal yang sangat erat kaitanya dengan motivasi belajar siswa salah satunya adalah guru.Guru adalah salah satu faktor yang dapat menentukan berbagai keberhasilan siswa dalam suatu proses pembelajaran dikelas. Untuk itu, profesionalitas seorang guru dalam suatu pembelajaran sangatlah perlu dan dirasakan penting. Seorang pendidik setidaknya memiliki empat kompetensi yaitu: kompetensi pedagogik, kompetensi sosial, kompetensi personal, dan kompetensi professional (Daryanto, 2013:18).

Kompetensi sosial dianggap penting dan harus dimiliki oleh seorang guru karena guru harus memiliki kemampuan untuk berkomunikasi secara efektif dengan peserta didik, sesama pendidik, tenaga kependidikan, orang tua/wali peserta didik, dan masyarakat sekitar. Guru diharapkan memiliki ketrampilan menciptakan suasana komunikasi yang baik, sehingga 
membuat siswa dapat berpartisipasi secara aktif untuk mengeluarkan pendapat serta mengembangkan imajinasi dan kreaktifitas. (Ardi Setyanto, 2017: 10).

Berdasarkan hasil observasi yang dilakukan peneliti di MI Muhammadiyah Potronayan 1 Nogosari Boyolali, masih banyak siswa yang memiliki motivasi belajar matematika yang masih rendah, saat pembelajaran masih banyak siswa takut salah ketika disuruh mengerjakan tugas matematika. Siswa cenderung diam dan malas belajar saat pembelajaran matematika. Permasalahan lainya juga ditemukan yaitu ditinjau dari cara mengajar guru belum maksimal, interaksi dengan siswa belum baik, guru belum mampu menggerakan siswa untuk melakukan interaksi yang membuat suasana kelas menjadi menyenangkan, nyaman dan tidak tertekan, tidak munculnya komunikasi dua arah atau feedback antara guru dan siswa, cara mengajar guru dianggap menoton. Hal ini dapat membuat proses belajar mengajar di dalam kelas menjadi kurang efektif dan efisien.

Menurut Widjaja dalam Ryan Adam Pratama, Rosita dan Diajeng (2016:115) kualitas komunikasi merupakan proses timbal balik (dua arah) antara sumber informasi dengan penerima pesan. Bila seseorang menyampaikan pesan kepada orang lain dan orang itu memberikan respon, maka proses komunikasi dapat dikatakan berlangsung secara efektif. Guru adalah pihak yang paling bertanggung jawab dalam proses belajar mengajar, sehingga guru dituntut untuk memiliki kualitas komunikasi dengan siswa agar menghasilkan proses belajar mengajar yang efektif (Nuriyanti dan Asriyati, 2016: 24). Bovee dan Thill dalam Haryani (2001: 89) proses komunikasi yaitu: 1)Pengirim mempunyai ide atau gagasan, 2) Ide diubah menjadi pesan, 3) Pesandikirim, 4) Penerima menerima pesan, 5) Penerima pesan bereaksi dan mengirim umpan balik. Rofingah dan mohammad (2018: 15-16) Aspek-aspekkualitas komunikasi guru dan siswa antara lain: 1) Keterbukaan, 2) Kejujuran, 3) Kepercayaan, 4) Empati, 5) Mendengarkan

Guru harus memiliki kualitas komunikasi dengan siswa agar dapat membangun suasana belajar yang menyenangkan. Suasana belajar yang menyenangkan berdampak pada kondisi psikologi siswa. Jika kualitas komunikasi guru dan siswa baik maka hubungan antara guru dan siswa akan baik dan harmonis. Ketika ada keharmonisan diatara keduanya maka siswa akan menyukai gurunya dan juga mata pelajarannya termasuk dalam mata pelajaran matematika.

Berdasarkan permasalahan yang terjadi. Permasalahan tersebut menarik untuk dikaji dengan judul hubungan kualitas komunikasi guru dan siswa dengan motivasi belajar 
matematika siswa kelas tinggi di MI Muhammadiyah se-Kecamatan Nogosari Boyolali tahun ajaran 2020/2021.

\section{METODE PENELITIAN}

Metode penelitian yang digunakan adalah kuantitatif korelasional . Penelitian ini bertujuan untuk mengetahui apakah terdapat hubungan kualitaskomunikasi guru dan siswa dengan motivasi belajar matematika siswa kelas tinggidi MI Muhammadiyah se-Kecamatan Nogosari Boyolali tahun ajaran 2010/2021. Populasi yang digunakan dalam penelitian ini adalah seluruh siswa kelas tinggi di MI Muhammadiyah se Kecamatan Nogosari Boyolali tahun ajaran 2020/2021. Pengambilan sampel dengan teknik cluster Sampling dengan sampel sebanyak 63 siswa. Teknik pengumpulan data dalam penelitian ini menggunakan angket. Uji normalitas menggunakan rumus Kolmogorov Smirnov dan demikian data berdistribusi normal. Uji hipotesis menggunakan rumus korelasi Product Moment.

\section{HASIL DAN PEMBAHASAN}

Berdasarkan angket kualitas komunikasi guru-siswa dan motivasi belajar matematika diperoleh hasil berupa skor. Hasil dari angket kualitas komunikasi gurudan siswa diperoleh skor terendah 96 dan skor tertinggi 145. Kemudian skor angketkualitas komunikasi guru dan siswa dibuat dalam table frekuensi dengan 3 kategoriyaitu, kurang sedang, dan baik. Sedangkan Hasil dari angket motivasi belajar matematika diperoleh skor terendah 89 dan skor tertinggi 144 . Kemudian skor angket kualitas komunikasi guru dan siswa dibuat dalam table frekuensi dengan 3 kategori yaitu rendah, sedang, dan tinggi.

Uji prasyarat dilakukan dengan menggunakan uji normalitas. Uji normalitasdilakukan untuk mengetahui apakah data berdistribusi normal atau tidak. Untuk melakukan uji normalitas data. Uji normalitas pada penelitian ini menggunakan ujicoba Kolmogorov-Smirnov. Syarat data dikatakan berdistribusi normal pada data penelitian adalah jika signifikansi atau a $>0,05$.

Tabel 1. Uji normalitas menggunakan uji Kolmogorov-Smirnov

\begin{tabular}{|c|c|c|c|c|}
\hline No & Variabel & Asymp Sig. & Taraf Sig. & Keputusan \\
\hline 1 & Kualitasi komunikasi gurudan siswa & 0,098 & 0,05 & Normal \\
\hline 2 & Motivasi belajarmatematika & 0,200 & 0,05 & Normal \\
\hline
\end{tabular}


Berdasarkan hasil perhitungan uji normalitas One-Sample Kolmogorov Smirnov dapat diketahui bahwa data variabel kualitas komunikasi guru dan siswa diperoleh nilai Asymp Sig. (2-tailed) sebesar 0,098 lebih besar dari 0,05, menunjukkan bahwa distribusi data dalam penelitian adalah normal. Hasil perhitungan uji normalitas One-Sample Kolmogorov Smirnov dapat diketahui bahwa data variabel motivasi belajar matematika diperoleh nilai Asymp Sig. (2- tailed) sebesar 0,200 lebih besar dari 0,05, menunjukkan bahwa distribusi data dalam penelitian adalah normal. Dengan demikian dapat disimpulkan bahwa data kualitas komunikasi guru dan siswa dengan motivasi belajar matematikaberdistribusi normal.

Koefisien determinasi $\left(\mathrm{R}^{2}\right)$ merupakan suatu ukuran yang menunjukkan besar sumbangan dari variabel bebas terhadap variabel terikat (Dergibson dan Sugiarto, 2000: 259). Koefisien determinasi memberikan informasi tentang proporsi keragaman atauvariasi total disekitar nilai tengah $\mathrm{Y}$ yang dapat dijelaskandengan regresi dugaan. Ukuran ini sering dinyatakan sebagai presentase dengan mengalikannya dengan 100.

Tabel.2 Koefisien Determinasi Kualitas Komunikasi Guru-Siswa Dengan Motivasi Belajar Matematika.

\begin{tabular}{cc}
\hline $\mathbf{R}$ & $\mathbf{R}$ Square $\left(\mathbf{R}^{2}\right)$ \\
\hline 0,422 & 0,178 \\
\hline
\end{tabular}

Berdasarkan perhitungan nilai koefisien determinasi atau $\mathrm{R}$ square $\left(\mathrm{R}^{2}\right)$, diketahui bahwa nilai koefisien determinasi adalah sebesar 17,8\%. Angka tersebutmengandung arti bahwa variabel kualitas komunikasi guru dan siswa berpengaruh terhadap variabel motivasi belajar matematika sebesar 17,8\%. Sedangkan sisanya dipengaruhi oleh variabel yang tidak diteliti 1) karakteristik tugas; 2) intensif; dan

3) pengaturan pembelajaran.

Pengujian hipotesis dengan menggunakan korelasi product moment dengan bantuan perhitungan SPSS untuk mengetahui hubungan keduanya. Hipotesis padapenelitian ini adalah terdapat hubungan positif antara kualitas komunikasi guru dansiswa dengan motivasi belajar matematika siswa kelas tinggi di MI Muhammadiyah se- Kecamatan Nogosari Boyolali tahun ajaran 2020/2021, diperoleh hasil sebagai berikut: 
Tabel 3. Korelasi komunikasi guru dan siswa dengan belajar matematika

\begin{tabular}{ccc}
\hline & Kualitas Komunikasi & Motivasi \\
\hline Korelasi Pearson & 0,422 & 0,422 \\
Sig. (2-tailed) & 0,001 & 0,001 \\
\hline $\mathrm{N}$ & 63 & 63 \\
\hline
\end{tabular}

Berdasarkan hasil uji korelasi di atas diperoleh dari kualitas komunikasi guru-siswa dan motivasi belajar matematika siswa kelas tinggi di MI Muhammadiyah se Kecamatan Nogosari Boyolali tahun ajaran 2020/2021 dengan $\mathrm{N}=63$, rhitung $=0,422$, rtabel $=0,244$, maka diperoleh rhitung 0,422 > rtabel 0,244, maka Ha diterima . dengan demikian dapat disimpulkan bahwa terdapat hubungan yang positif antara kualitas komunikasi guru dan siswa dengan motivasi belajar matematika siswa kelas tinggi di MI Muhammadiyah se- Kecamatan Nogosari Boyolali tahun ajaran 2020/2021. Hal ini sejalan dengan penelitian Wahyuni (2014) yang membuktikan bahwa terdapat hubungan yang signifikan komunikasi interpersonal guru dan siswa dengan motivasi belajar matematika. Menurut Turmudi (2008) siswa apat belajar dengan efektif apabila mereka tertarik dengan apa yang mereka sukai, seperti halnya dalam kegiatan belajar, apabila ssiwa tertarik dengan apa yang mereka pelajari, maka akan mempenagruhi prestasi belajarnya. Sehingga perlu sekali untuk menciptakan, mengembangkan, memberika dorongan terhadap matapelajaran yang dianggap sulit oleh siswa. Berdasarkan penelitian Wulandari (2016) salah satu cara untuk bisa menarik siswa menyukai matapejaran yang kurang disukainya adalah melalui metode pembelajaran kooperatif. Metode kooperatif akan menigkatkan komunikasi dalam proses pembelajaran.

Menurut (Urea, 2013; Sucia, 2017) gaya komunikasi guru mempengaruhi gaya belajar dari siswa. Urea (2013) menjelaskan gaya komunikasi, guru yang cenderung assertive (disiplin) akan memicu siswa untuk termotivasi dalam belajar dan mendekatkan guru dengan siswa, sedangkan non assertive merupakan kecenderungan guru untuk berdiam apabia terdapat suatu masalah, sedangkan gaya komunikasi agresive akan mendekatkan diri disetiap kesempatan pada siswa.

Gaya komunikasi yang menyenangkan akan menumbuhkan motivasi belajar bagi siswa. Prapanca (2012) menyatakan bahwa dalam proses belajar mengajar dipengaruhi oleh beberapa faktor, dan salah satunya dipengaruhi oleh hubungan anatar guru dan siswa di kelas. Diawali dari rasa nyaman dan suka terhadap cara guru mengajar, kemudian akan menimbulkan rasa sungguh-sungguh untuk belajar dan akhirnya akan menyukai matapejaran guru tersebut. Rasa sungguh-sungguh untuk belajar ini merupakan motivasi belajar siswa untuk bisa lebih semangat 
dan giat dalam belajar. Menurut Yaqinah (2014) komunikasi interpersonal merupakan gaya komunikasi yang mendukung dalam mengubah sikap, opini, dan perilaku, sehingga menurut akan berpengaruh terhada prestasi belajar siswa (Onibala, 2019).

Menurut De Vito dalam Thoha (1990) karakteristik dari komunikasi interpersonal adalah keterbukaan (openess), dukungan (supportiveness), kepositifan (positivenes), empati (empathy), dan kesamaan (equality). Komunikasi yang mampu menciptakan dan meningkatkan efektivitas hubungan antara manusia atau kelompok baik dalam komunikasi verbal maupun non verbal. Gerakangerakan seperti anggukan kepala, kedipan mata, acungan jempol, senyuman atau tepukan tangan merupakan dukungan positif yang tidak diucapkan (Onibala, 2019).

Faktor yang mempengaruhi keberhasilan komunikasi diantaranya: a) Komunikator (Pengirim Pesan); b) Pesan yang disampaikan; c) Komunikan (Penerima Pesan); d) Konteks ; Komunikasi berlangsung dalam setting atau lingkungan tertentu; e) Sistem Penyampaian ; Sistem penyampaian berkaitan dengan metode dan media (Wardani, 2005). Proses pembelajaran maematika membutuhkan komunikasi yang efektif, terutama guru dengan siswa. Seorang guru matematika harus dapat mengkomunikasikan pikiran matematisnya melalui lisan maupun tulisan dengan jelas, dan menggunakan bahsa matematika agar dapat mengekspreikan gagasan maupun ide dengan tepat, serta mengelola pemikiran matematisnya melalui komunikasi, menganalisis dan mengevaluasi pikiran matematis siswanya (Lanani, 2013).

\section{KESIMPULAN}

\section{Simpulan}

Berdasarkan pada hasil penelitian dan pembahasan yang telah penulisuraikan pada bab sebelumnya, maka dapat ditarik kesimpulan terdapat hubungan yang positif antara variabel kualitas komunikasi guru dan siswa dengan motivasi belajar matematika. Makna dari hubungan yang positif sendiri adalah hubungan antara 2 variabel dimana kenaikan satu variabel menyebabkan penambahan nilai pada variabel lainnya atau sebaliknya. Dengan demikian dapat disimpulkan bahwaterdapat hubungan yang positif antara kualitas komunikasi guru dan siswa dengan motivasi belajar matematika siswa kelas tinggi di MI Muhammadiyah se- Kecamatan Nogosari Boyolali tahun ajaran 2020/2021 


\section{DAFTAR PUSTAKA}

Daryanto. (2013). Standard kompetensi dan penilaian kinerja guru profesional. Yogyakarta: Gava Media

Dirgibson Siagian dan Sugiyarto. (2000). Metode statistika untuk bisnis danekonomi. Jakarta: PT Gramedia Pustaka Utama.

Kompri. (2017). Belajar faktor-faktor yang mempengaruhinya.Yogyakarta: MediaAkademi.

Lanani, K. (2013). Belajar berkomunikasi dan komunikasi untuk belajar dalam pembelajaran matematika. Infinity Journal, 2(1), 13-25

Lasompo, N., \& Nadjamuddin, A. (2020). Pengaruh komunikasi antara guru dan siswa terhadap motivasi belajar siswa kelas $\mathrm{v}$ di sdn 1 paku kecamatan bolangitan barat. Educator (directory of elementary education journal), 1(1), 22-34.

Lestari, W. (2017). Pengaruh kemampuan awal matematika dan motivasi belajar terhadap hasil belajar matematika. Jurnal Analisa, 3(1), 76-84

Muhammad Fathurrohman dan Sulistyorini. (2012). Belajar pembelajaran meningkatkan mutu pembelajaran sesuai standar nasional. Yogyakarta:Teras.

Onibala, T., Mingkid, E., \& Kalesaran, E. R. (2019). Pola Komunikasi Guru Dalam Mendidik Anak Autis Di Agca Center Pumorow Manado. ACTA DIURNA KOMUNIKASI, 8(2)

Prapanca, T. (2012). Minat siswa kelas IX terhadap mata pelajaran tata boga di SMA N 1 Temon. Skripsi. Fakultas Teknik Universitas Negeri Yogyakarta.

Pratama, R. A. (2017). Kualitas komunikasi interpersonal dosen dan motivasi mahasiswa dalam menulis skripsi. Inter komunika, 2(2), 114-122.

Setyanto, A. (2017). Interaksi dan komunikasi efektif belajar-mengajar. Yogyakarta: DIVA Press (Anggota IKAPI)

Sucia, V. (2017). Pengaruh gaya komunikasi guru terhadap motivasi belajar siswa. Komuniti: Jurnal Komunikasi Dan Teknologi Informasi, 8(5), 112-126.

Ridwan Abdullah Sani. (2016). Inovasi Pembelajaran. Jakarta: PT Bumi Aksara.

Rofingah, N., \& Mahpur, M. (2018). Efektifitas komunikasi berkualitas untuk meningkatkan kehangatan dalam pengasuhan pada orangtua sibuk bekerja di KB-TK IT AlHikmah. Psikoislamika: Jurnal Psikologi dan Psikologi Islam, 15(2), 12-20.

Sri Haryani. (2001). Komunikasi Bisnis. Yogyakarta: Unit Penerbit.

Thoha, M. (1990). Kepemimpinan dan manajemen (Suatu Pendekatan Perilaku). Sinar Baru: Bandung

Urea, R. (2013). The impact of teachers' communication styles on pupils' self-safety throughout the learning process. Procedia-Social and Behavioral Sciences, 93, 164-168

Wahyuni, S. (2014). Hubungan komunikasi interpersonal guru dan siswa dengan motivasi belajar matematika di kelas XI Madrasah Aliyah Swasta Al Azhar Bi Ibadillah Ujung Gading Tahalak (Doctoral dissertation, IAIN Padangsidimpuan.

Wardani, IGAK. (2005). Dasar-Dasar Komunikasi dan Keterampilan Dasar Mengajar. Jakarta: PAU-DIKTI DIKNAS.

Wulandari, W. S. (2016). Meningkatkan kemampuan komunikasi dan motivasi belajar matematika siswa sekolah dasar melalui pembelajaran kooperatif tipe think-pairshare. EduHumaniora| Jurnal Pendidikan Dasar Kampus Cibiru, 7(2), 198-208.

Yaqinah, S. N. (2014). Implikasi komunikasi interpersonal terhadap perubahan sikap individu. Jurnal Komunike, 6(1), 39-50. 